\title{
Pelizaeus Merzbacher disease: dysmyelination versus demyelination
}

Doença de Pelizaeus Merzbacher: dismielinização versus desmielinização

Karina Akinaga, Tiffany Yi Huei Lee, Maria Augusta Montenegro

Pelizaeus Merzbacher disease is characterized by abnormal myelin formation. In most patients it is caused by a X linked recessive mutation in the PLP1 gene. Typically, the disease begins in the first two months of life, but milder variations may not be present until childhood.

Symptoms include severe developmental delay, problems with feeding, hypotonia, nystagmus, spasticity, cerebelar ataxia, seizures and developmental delay ${ }^{1}$. Brain MRI shows abnormal white matter signal on T2 and FLAIR images, without abnormal signal on T1 images; therefore, suggesting dysmyelination ${ }^{2,3}$. There is no reverse gray-white matter contrast in both $\mathrm{T} 1$ and $\mathrm{T} 2$ images (usually seen in demyelination, myelin destruction) (Figure).

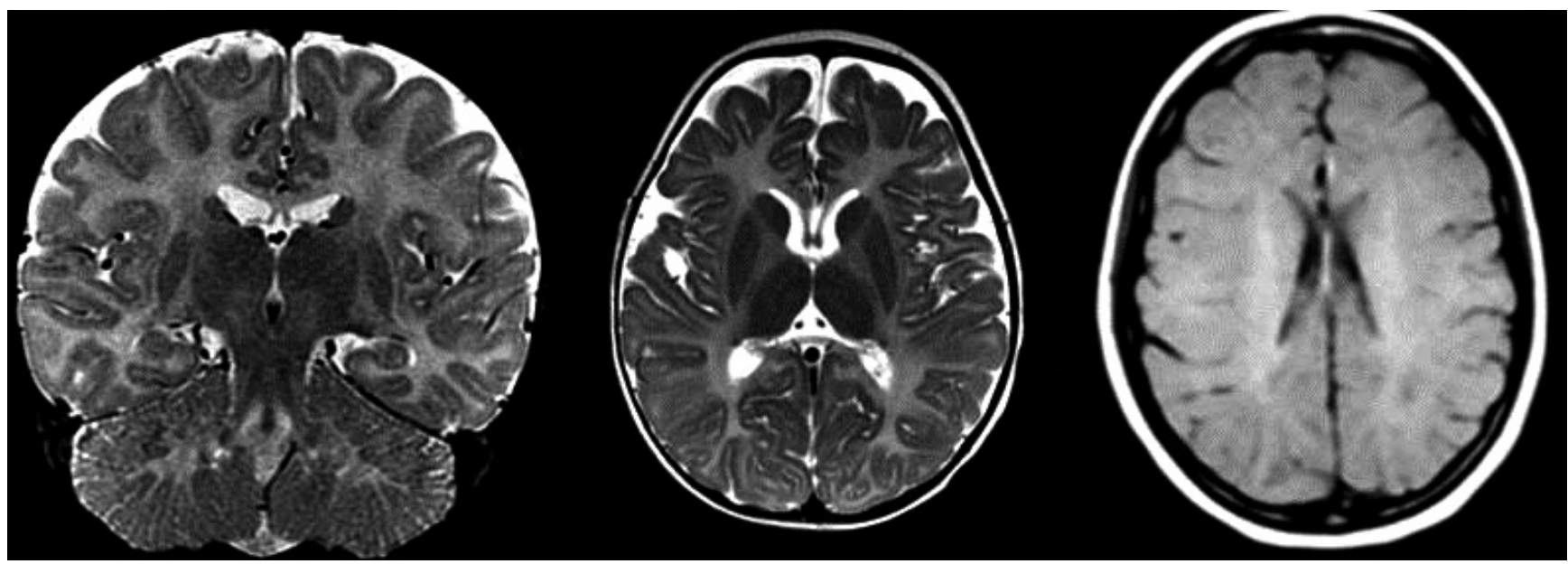

Figure. MRI of a 24-month-old boy with severe developmental delay since birth. Neurological examination disclosed axial hypotonia, hyperreflexia, and horizontal nystagmus. Coronal T2 and Axial T2 images shows diffuse hyperintense signal in the white matter. Note that in the axial T1 image there is no hypointense signal in the white matter, which suggests dysmyelination (abnormal myelin structure).

1. Boulloche J, Aicardi J. Pelizaeus-Merzbacher disease: clinical and nosological study. J Child Neurol. 1986;1(3):233-9. doi:10.1177/088307388600100310

2. Pizzini F, Fatemi AS, Barker PB, Nagae-Poetscher LM, Horská A, Zimmerman AW et al. Proton MR spectroscopic imaging in Pelizaeus-Merzbacher disease. AJNR Am J Neuroradiol. 2003;24(8):1683-9.

3. Barkovich AJ. Concepts of myelin and myelination in neuroradiology AJNR Am J Neuroradiol. 2000;21(6):1099-109. 